\title{
Endovascular repair of a juxtarenal saccular aneurysm using the Multilayer Flow Modulator: report of the first case performed in a Public Hospital in Brazil
}

\author{
Tratamento de aneurisma de aorta sacular justarrenal com Multilayer Flow \\ Modulator: relato do primeiro caso realizado em Hospital Público no Brasil \\ Rodrigo Gibin Jaldin', Marcone Lima Sobreira', Regina Moura', Matheus Bertanha', \\ Jamil Víctor de Oliveira Mariaúba', Rafael Elias Farres Pimenta', \\ Ricardo de Alvarenga Yoshida', Winston Bonetti Yoshida
}

\begin{abstract}
Endovascular treatment of abdominal aortic aneurysms (AAA), involving the exits of the renal and visceral arteries still constitutes a considerable challenge. Many different techniques have been developed over the years in attempts to surmount the difficulties presented by these cases. Techniques that have gained prominence include fenestrated or branched stents, methods involving parallel prostheses, such as the chimney, periscope and sandwich techniques, and, more recently, flow modulation with Multilayer stents. We describe a case of a complex juxtarenal saccular AAA with a high surgical risk, both according to cardiological assessment and because the patient had a difficult airway caused by a total laryngectomy for early stage laryngeal neoplasm. In view of the technical simplicity of using Multilayer stents, the presence of chronic obstructive aortoiliac disease, ostial stenosis of the renal artery and a small diameter suprarenal aorta, options involving fenestrated/branched stents and techniques involving parallel prostheses were ruled out, because of the need for multiple accesses. In view of the dilemma it presented, we describe this case as a therapeutic challenge and present the treatment option employed, which has been successful over the short term.
\end{abstract}

Keywords: aorta; aneurysm aortic; endovascular procedures.

\begin{abstract}
Resumo
O tratamento endovascular de aneurismas de aorta abdominal (AAA), envolvendo a saída das artérias renais e viscerais, constitui ainda um importante desafio. Diversas técnicas foram desenvolvidas ao longo do tempo para contornar as dificuldades oferecidas por esta situação, destacando-se as endopróteses fenestradas ou ramificadas, as técnicas envolvendo próteses paralelas, como Chaminé, Periscópio e Sanduíche, e, mais recentemente, a utilização da modulação de fluxo por stent multicamadas Multilayer. Apresentamos um caso de AAA sacular complexo justarrenal e com alto risco cirúrgico pela avaliação cardiológica e por apresentar via aérea difícil, em decorrência de laringectomia total por antecedente de neoplasia de laringe. Devido à facilidade técnica do uso do Multilayer, à presença de doença obstrutiva crônica aorto-ilíaca, à estenose ostial renal e ao diâmetro limitado da aorta suprarrenal, descartaram-se as opções envolvendo endopróteses fenestradas/ramificadas ou técnicas envolvendo próteses paralelas, pela necessidade de diversos acessos para a execução. Diante do dilema imposto, apresentamos este caso como desafio terapêutico e com uma opção de tratamento bem sucedida, em curto prazo.
\end{abstract}

Palavras-chave: aorta; aneurisma aórtico; procedimentos endovasculares.

\footnotetext{
TUniversidade Estadual Paulista - UNESP, Faculdade de Medicina de Botucatu, Botucatu, SP, Brazil. Financial support: None.

Conflicts of interest: No conflicts of interest declared concerning the publication of this article. Submitted: 04.18.14. Accepted: 05.15.14.
}

The study was carried out at the Department of Surgery and Orthopedics, Faculdade de Medicina de Botucatu - Universidade Estadual Paulista (UNESP), São Paulo, Brazil. 


\section{INTRODUCTION}

Endovascular treatment of abdominal aortic aneurysms (AAA) that involve the exits of the renal and visceral arteries is a considerable challenge, particularly in patients at high surgical risk. Several alternative techniques to conventional surgery have been developed over the years in attempts to surmount the difficulties presented by these cases. Techniques that have gained prominence include hybrid surgery or "debranching," fenestrated or branched stents, ${ }^{2}$ the chimney (or snorkel), Periscope and Sandwich techniques ${ }^{3}$ and, more recently, flow modulation with Multilayer stents. ${ }^{4-14}$ We describe the case of patient with very high cardiological surgical risk and multiple comorbidities suffering from a juxtarenal saccular AAA. The patient's condition meant that conventional surgery would be high risk; the patient also had a history of laparotomy and segmental enterectomy because of mesenteric ischemia. Vascular access was limited by chronic obstructive aortoiliac disease and by hostile neck anatomy, caused by cervical lymph node dissection, laryngectomy and cervical radiotherapy, in addition to ostial stenosis of the left renal artery, throwing up technical obstacles to execution of options involving branched and fenestrated stents or parallel prostheses. In view of the dilemma it presented, we describe this case of a therapeutic challenge and the treatment option employed, which has proved successful in the short term.

\section{PART I - CLINICAL SITUATION}

A male, 62-year-old ex-smoker with hypertension and a history of laparotomy for mesenteric ischemia ten years previously and prior treatment of laryngeal neoplasm by total laryngectomy, cervical clearance and radiotherapy. As part of postoperative followup for neoplasm staging, an abdominal computed tomography scan was performed, revealing a saccular aneurysm of the aorta, immediately below the origin of the renal arteries. The patient complained of intermittent claudication in the left lower limb at 100 meters. On physical examination only the right femoral pulse was palpable in the lower limbs, while other pulses were absent. The best ankle-brachial indices for the lower limbs were the posterior tibials, at 0.59 on the right and 0.43 on the left. Laboratory test results showed creatinine varying from 1.2 to 1.4 , with no other significant abnormalities. The patient's cardiological assessment classified risk of cardiovascular events as moderate, following the latest preoperative assessment recommendations from the Sociedade Brasileira de Cardiologia. Multi-slice angiotomography was conducted with post analysis in an Osirix system, with the following findings: there was a saccular aneurysm intimately involving the right renal artery, with a mural thrombus splitting the right renal artery upwards, located at the level of the left renal artery; stenosis ostial of the left renal artery; occlusion of the left common iliac; moderate stenosis of right common and external iliac arteries; in addition to identifying several renal polar arteries and the inferior mesenteric artery as vicarious, supplying collateral circulation to the left iliofemoral axis. The cross-sectional diameter of the suprailiac aorta - a landing zone for possible endovascular intervention - measured $25.8 \mathrm{~mm}$. The cross-sectional diameter of the aorta at the height of the origin of the right renal artery (the upper renal artery) measured $19 \mathrm{~mm}$. The diameter of the sacculation in isolation was approximately $30 \mathrm{~mm}$; and the total diameter of the aorta in the topography of the saccular aneurysm was approximately $50 \mathrm{~mm}$. The extent of the aneurysmal lesion was approximately $35 \mathrm{~mm}$. The distance from the lower renal artery (left renal) to the aortic bifurcation was $102 \mathrm{~mm}$. The extension of the right internal iliac artery was approximately $45 \mathrm{~mm}$. The distances between visceral arteries were as follows: $12.5 \mathrm{~mm}$ from right renal to superior mesenteric and $9.5 \mathrm{~mm}$ from superior mesenteric to celiac trunk (Figures 1 and 2).

Faced with this presentation, a number of treatment options were discussed:

1- Hybrid surgery;

2- Fenestrated stent (commercial or customized);

4- Branched stent;

5- Parallel endoprostheses (chimney, snorkel, periscope or sandwich);

6- Multilayer Flow Modulator.

\section{PART II - WHAT WAS DONE}

The decision was taken to attempt endovascular repair of the aneurysm using a Multilayer Flow Modulator (MFM). The procedure was conduced under spinal anesthesia, in view of the patient's difficult airway. A small transverse incision was made $2 \mathrm{~cm}$ above the inguinal fold, followed by dissection, exposure and proximal and distal control of the right common femoral artery and then puncture of the right common femoral artery followed by the Seldinger technique and catheterization with a $11 \mathrm{~cm} \mathrm{6F}$ introducer sheath. Aortography with a Pig Tail 5F catheter, using a Left Anterior Oblique 


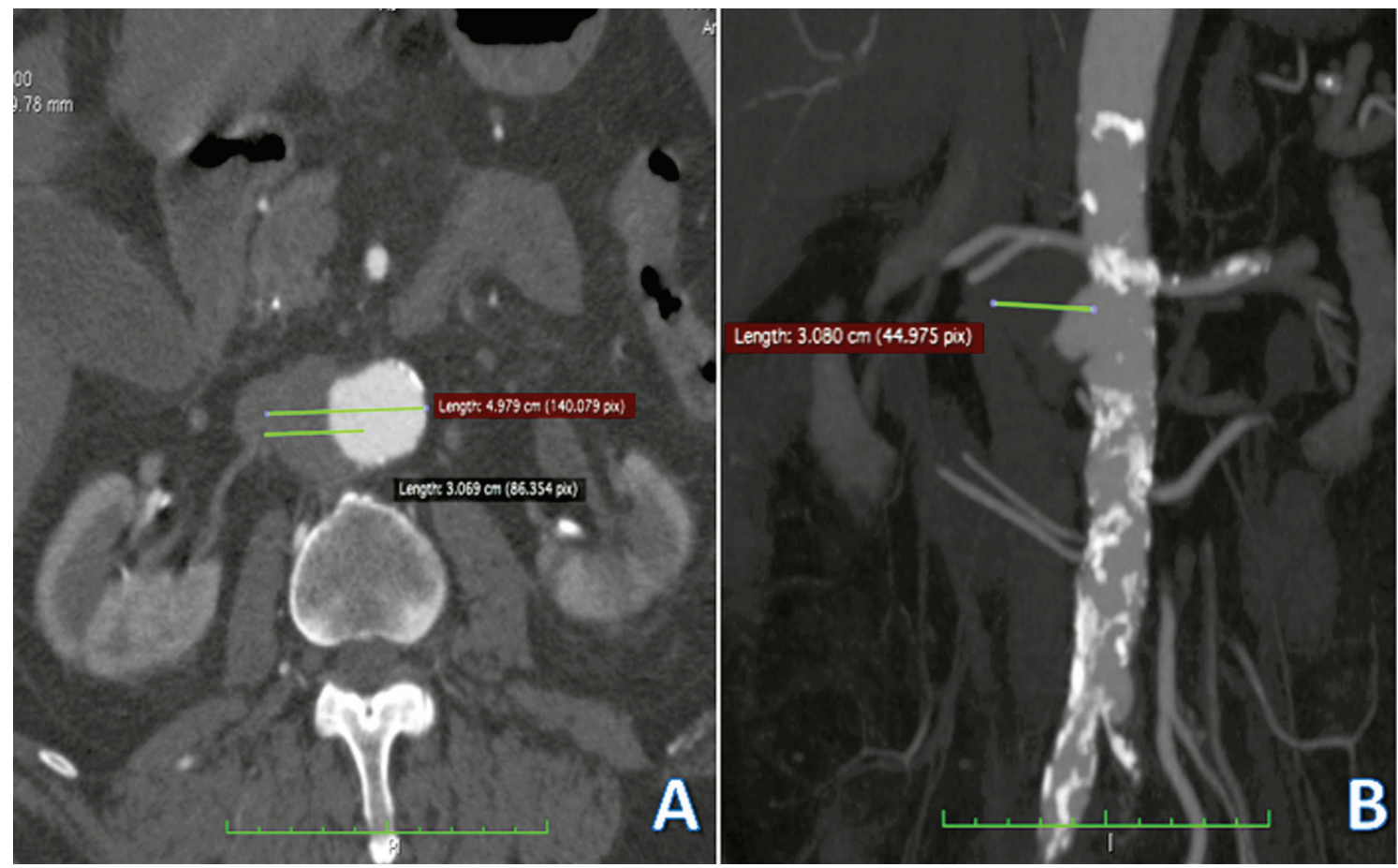

Figure 1. Angiotomography showing the saccular aneurysm close below the emergence of the right renal artery. A) Transverse section at the height of the aneurysm, showing measurements of the diameters of the whole aorta and the saccular portion in this topography. B) Angiotomography reconstruction in coronal multiplanar reformatting. Note the polar arteries.
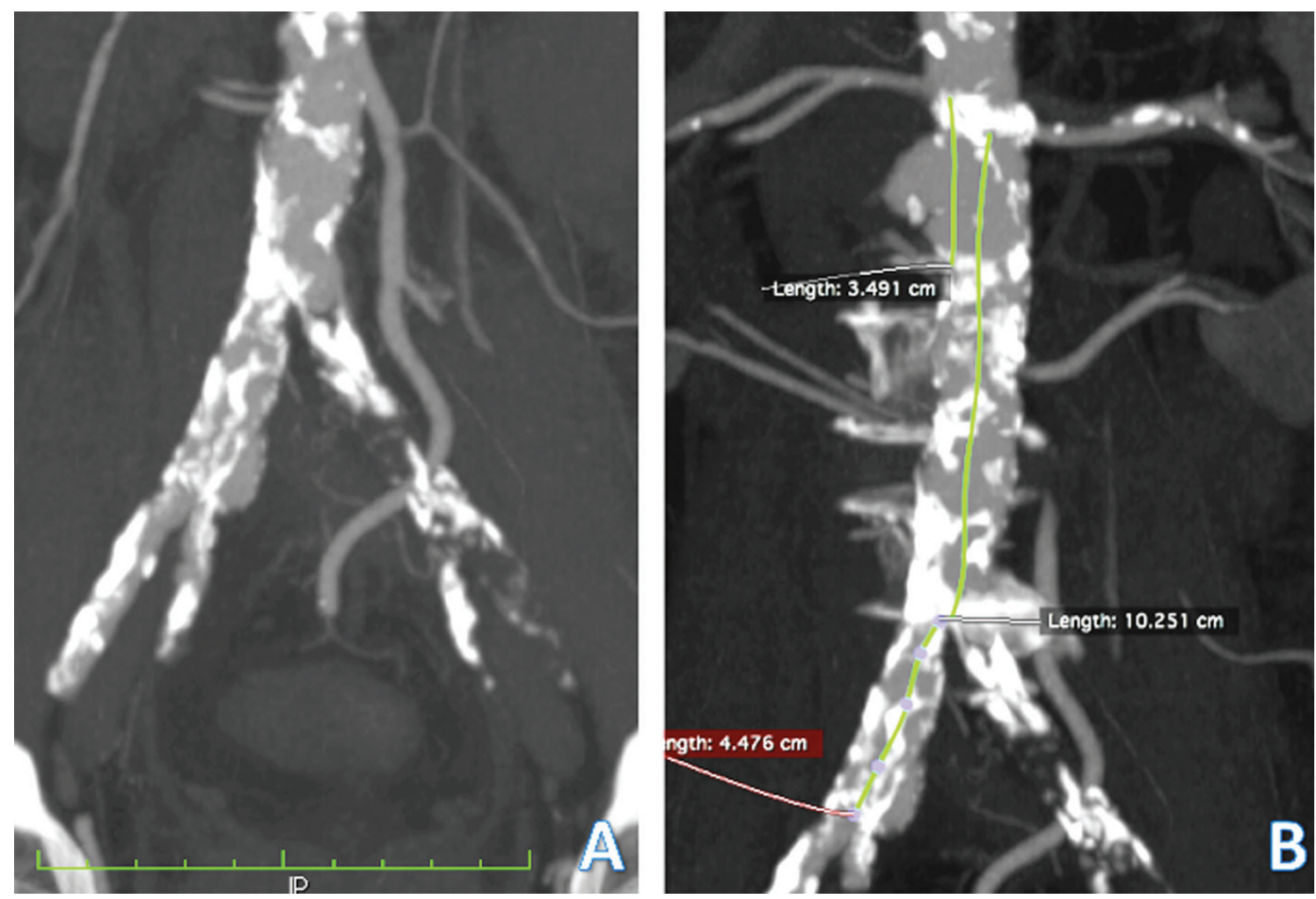

Figure 2. Angiotomography reconstruction in coronal multiplanar reformatting. A) Stenosis of the right iliac axis, occlusion of the left internal iliac artery and vicarious inferior mesenteric artery. B) Measurements of infrarenal aorta extensions for preoperative planing. 
(LAO) view at $20^{\circ}$, revealed critical ostial stenosis of the left renal artery (Figure 3 ) requiring treatment before placement of the Multilayer stent, as directed by the manufacturer's technical recommendations (Instructions for Use). To accomplish this the introducer was changed for a $40 \mathrm{~cm}$ Flexor $6 \mathrm{~F}$ wired introducer (Cook Medical), followed by systemic heparinization and selective catheterization of the left renal artery in a coaxial system with a Renal Double Curve (RDC) $5 \mathrm{~F}$ catheter on a $260 \mathrm{~cm}$ 0.035 " stiff hydrophilic guide wire (Terumo). The guide wire was then changed for a $180 \mathrm{~cm} 0.014$ " PT2 moderate support guide (Boston Scientific) and the lesion in the renal artery was pre-dilated with a $4 \times 20 \mathrm{~mm}$ Pacific Xtreme balloon (Medtronic). The lesion was then treated using a $5.5 \times 15 \mathrm{~mm}$ Hippocampus balloon-expandable stent (Medtronic), using the conventional technique of tractioning the balloon to the make a flair in the aortic portion of the stent after release of the stent. Having treated the renal lesion, a pre-treatment aortography was conducted using a 5F Pig Tail catheter with $\mathrm{cm}$ scale to advance an extra-stiff $300 \mathrm{~cm} 0.035$ " E-wire guide (Jotec), followed by removal of the introducer and placement of the MFM delivery device (Figure 4). A Multilayer Flow Modulator measuring $28 \times 100 \mathrm{~mm}$ (Cardiatis) was released by a pull-back mechanism, from the suprailiac aorta to the medial portion of the proximal right internal iliac artery (Figure 5). The mesh of the MFM was in contact with the aorta wall along a total extension of approximately $170 \mathrm{~mm}$ (after extension), extending into the aneurysmal disease-free aorta approximately $6 \mathrm{~cm}$ proximal and $9 \mathrm{~cm}$ distal of the lesion. The distal extremity of the MFM was prevented from opening completely in the right internal iliac artery by extrinsic compression exerted by calcifed plaques. In view of this, the decision was taken to use ballooning to fit the distal extremity of the MFM, using a low complacency Reef HP $8 \times 60 \mathrm{~mm}$ balloon (Medtronic), with recoil. At this point, angioplasty of the calcifed lesions in the common iliac was conducted by releasing a Scuba $9 \times 55 \mathrm{~mm}$ balloon-expandable stent (Medtronic) into a position at which there was approximately $15 \mathrm{~mm}$ of overlap with the MFM (Figure 6). Control aortography showed an immediate reduction in opacification of the saccular aneurysm, suggesting that the flow into it had reduced, and no sign of complications related to the treatments administered were identified (Figure 7). The patient remained in the intensive care unit for $24 \mathrm{~h}$ during the postoperative period and was discharged from hospital on the fourth day after operating, without suffering any type of intercurrent clinical condition in the meantime. Duplex mapping was conducted immediately before hospital discharge and Color and Doppler modes showed no flow into the aneurysm sac. The patient was seen again at 2 months, was asymptomatic and on double antiplatelet treatment. Duplex mapping and angiotomography were conducted once more, showing effective exclusion of the saccular aneurysm (Figure 8).
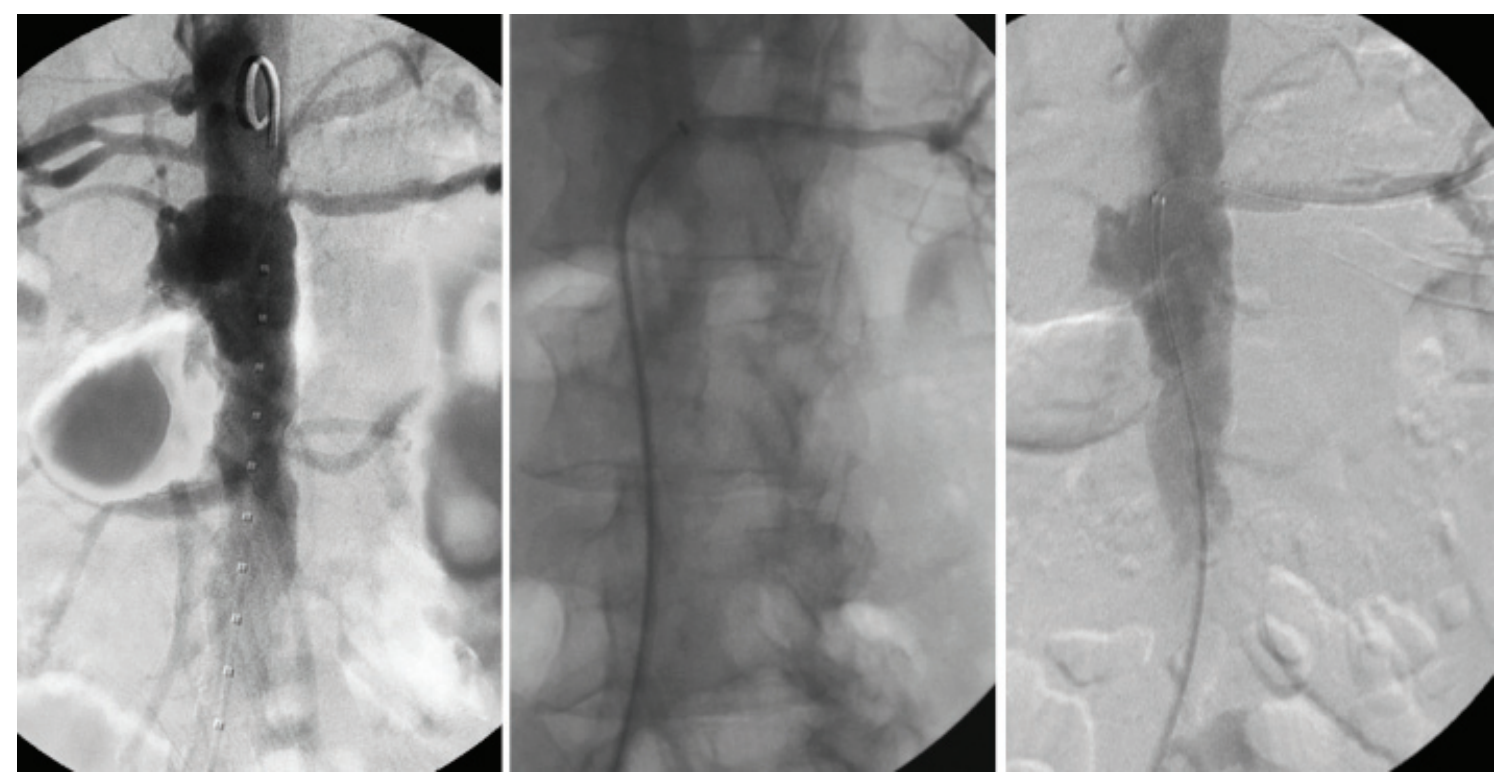

Figure 3. Preoperative aortography in $\mathrm{LAO}$ at $20^{\circ}$ and stent angioplasty of left renal artery. 

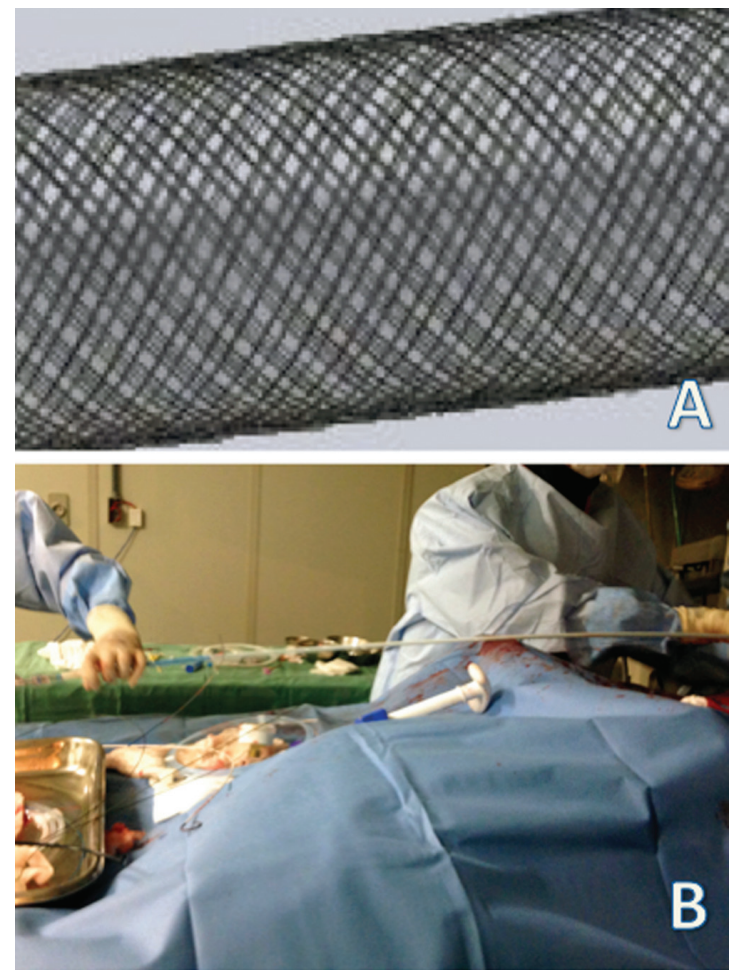

Figure 4. A) Multilayer Flow Modulator. B) Multilayer Flow Modulator release system, which has an $18 \mathrm{~F}$ profile, runs along a $0.035^{\prime \prime}$ guide wire and has a pull-back style release mechanism.

\section{DISCUSSION}

Juxtarenal AAA or AAA involving visceral arteries (also known as thoracoabdominal) are challenging to treat. While conventional surgery is effective and durable,${ }^{15}$ it is associated with greater invasivity and considerable morbidity and mortality, particularly among patients at high operative risk. Continuous development of materials by the industry has allowed endovascular treatment to become established as an important alternative operating technique for AAA, particularly for patients with favorable anatomy. However, for patients with unfavorable anatomy, such as short neck $(<15 \mathrm{~mm})$ or juxtarenal position, or where other visceral branches are involved, the standard designs of normal commercial prostheses were unsuitable. The inventiveness of surgeons led to the proposal of implanting branches through fenestrations and branches in the main body of commercial endoprostheses, and also to the development of branched stents. The former are effective but time-consuming and are experimental techniques that have not yet been clearly validated (off-label). ${ }^{16}$ In contrast, branched stents have industry support, but are expensive and take a long time to be manufactured (off-the-shelf) to fit the
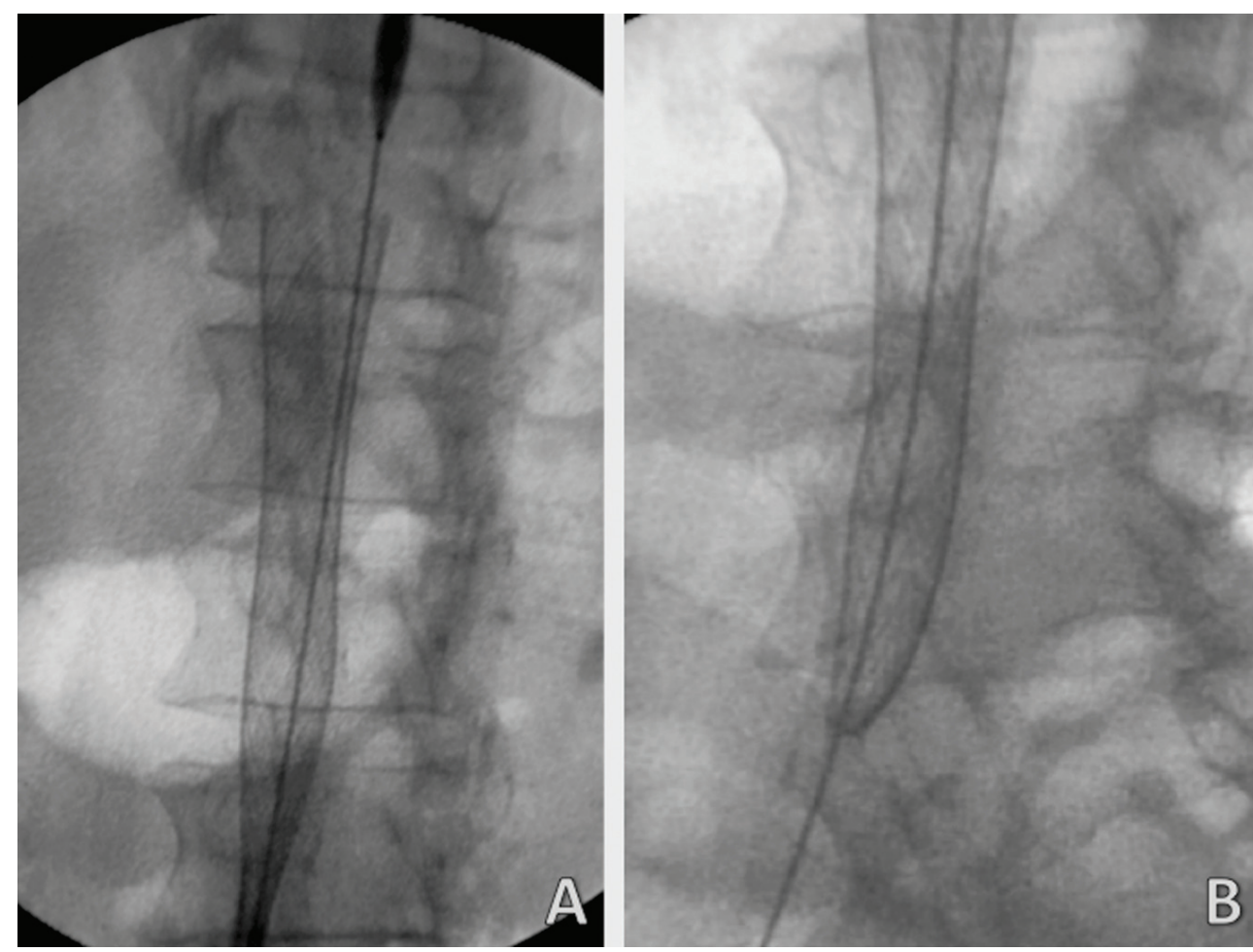

Figure 5. Release of Multilayer Flow Modulator. A) Position of proximal extremity of stent (landing zone) at the medial point of vertebra T12 (suprailiac aorta). B) Distal extremity of stent prevented from opening completely by extrinsic compression from calcifed plaques in the right internal iliac artery. 

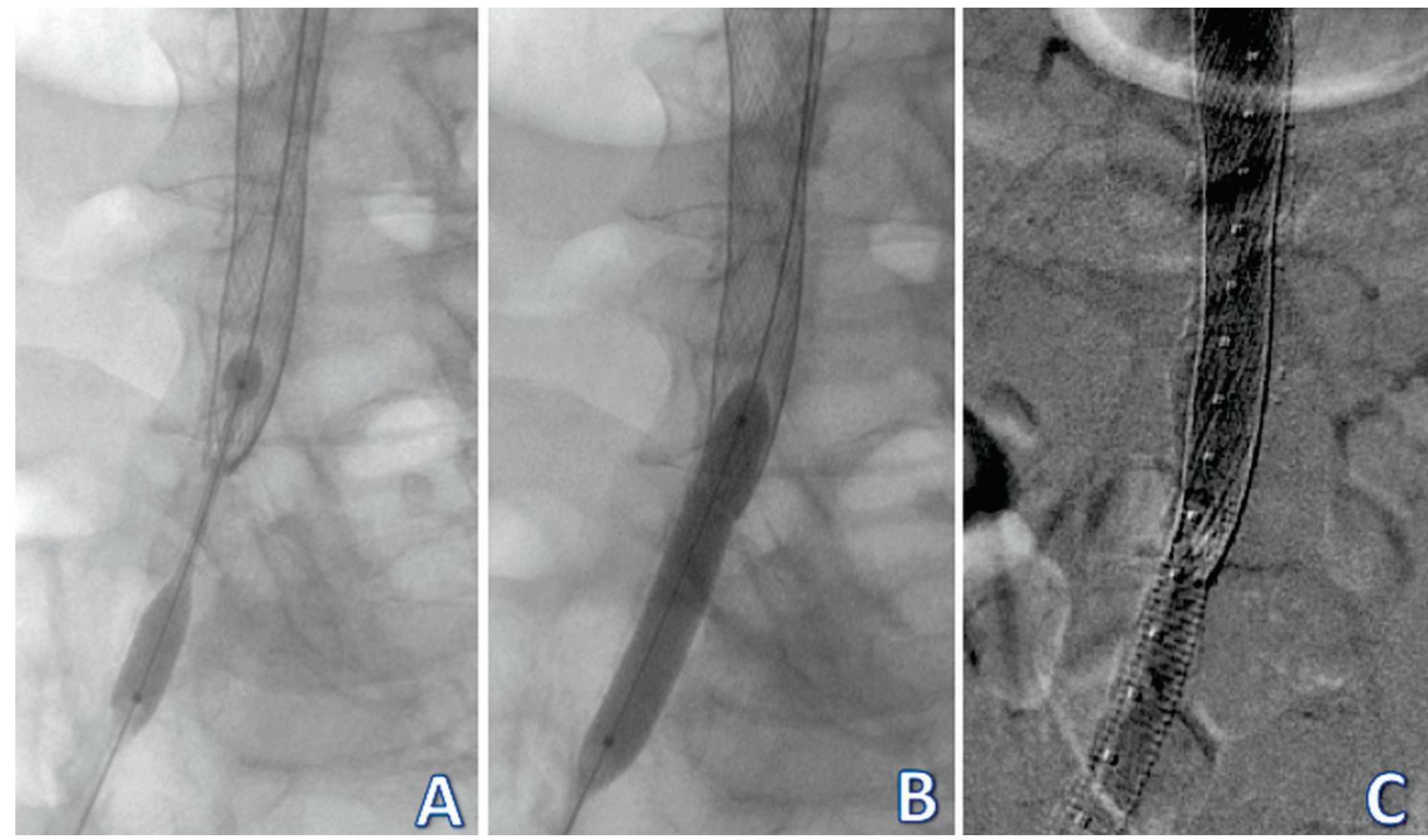

Figure 6. Angioplasty to fit the distal extremity of the Multilayer Flow Modulator. A) Deformation of the low complacency balloon provoked by the intensely calcifed plaque. B) Effective dilation of the lesion. C) Release of the balloon-expandable stent into a position extending from the MFM to the right internal iliac artery.
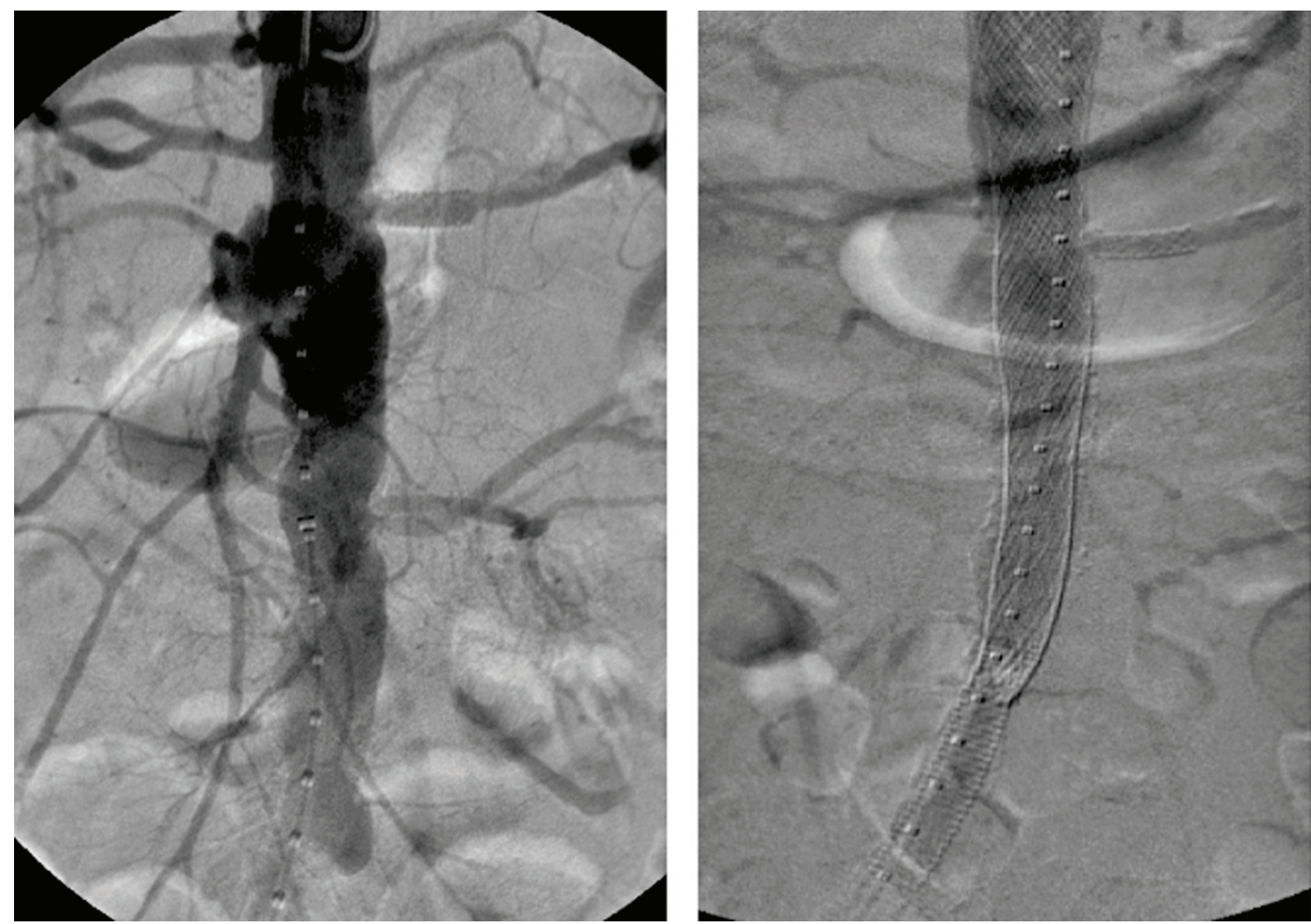

Figure 7. Pre-treatment and final post-treatment control aortographies. 

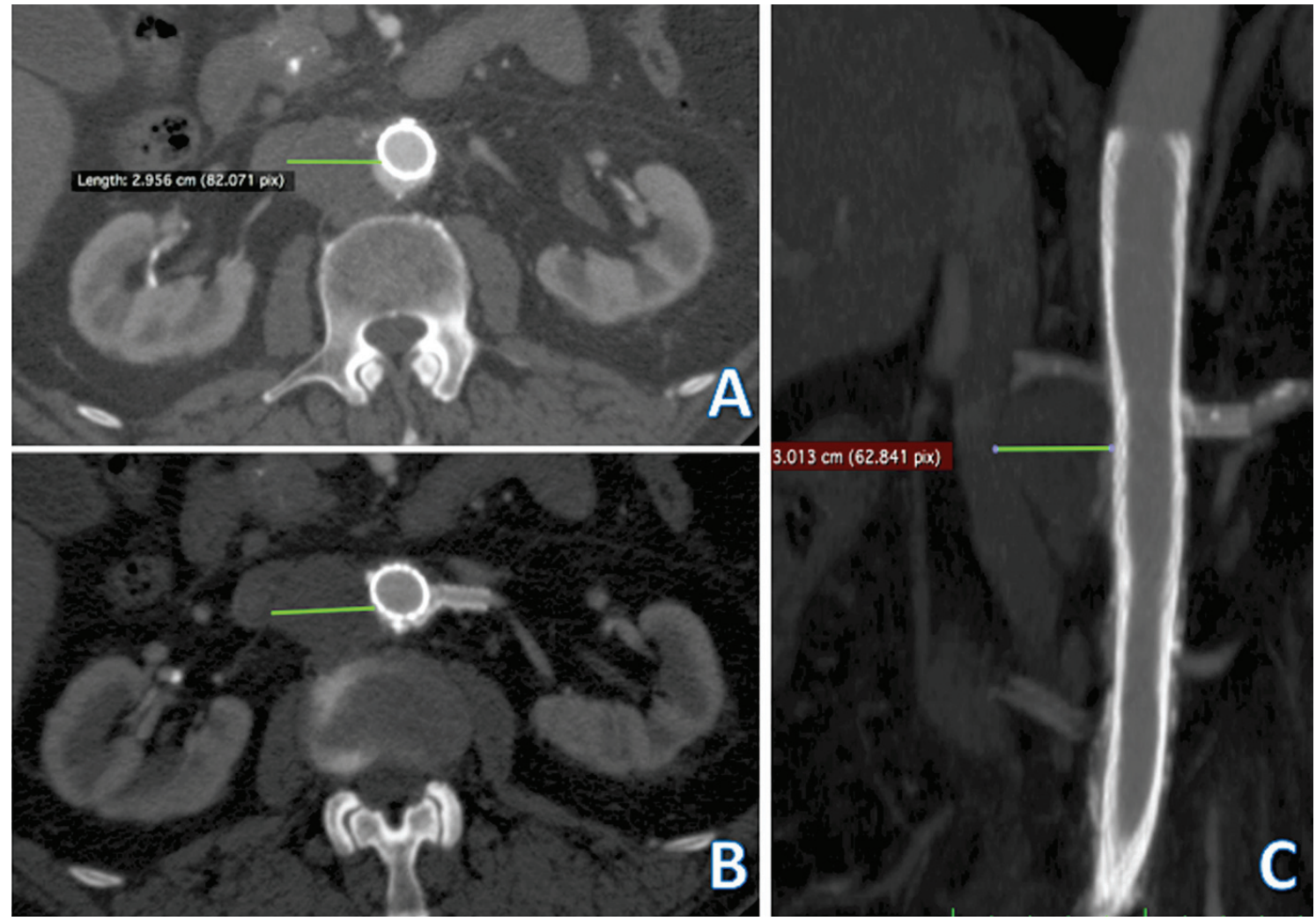

Figure 8. Postoperative control angiotomography at 60 days showing the thrombosed saccular aneurysm. A) Transverse section immediately above the origin of the left renal artery, showing a discrete sheet of contrast external to the MFM, formation of thrombi in the interior of the aneurysm sac and discrete reduction of the diameter of the sac in this topography. B) Saccular aneurysm totally thrombosed at the height of the left renal artery, which has a patent stent inside it. C) Angiotomography reconstruction in coronal multiplanar reformatting.

anatomy of each patient. ${ }^{17}$ Less expensive alternatives that are more widely available and easier to perform include chimney, snorkel and sandwich techniques. ${ }^{3}$ One of the major challenges of these techniques is how to avoid gutters and leaking endoprostheses with the many different chimneys needed to maintain blood flow in visceral arteries. ${ }^{18,19}$

More recently, a new concept in treatment of arterial aneurysms was introduced with Multilayered uncovered self-expanding stents that offer high radial strength and are manufactured from fibers woven from cobalt alloy (Phynox): known commercially as the Multilayer Flow Modulator (MFM), the objective of this type of stent is to redirect blood flow in such a manner as to remove pressure from within the aneurysm sac, preventing it from rupturing..$^{5-8,10-12}$ The MFM's three-dimensional arrangement of threads in layers is designed to be capable of changing the flow regime in the aneurysm sac interior from turbulent to laminar, encouraging the formation of organized and stable thrombi in the interior of the sac. Successful clinical results in the form of thrombosis of the aneurysm, reduction of the aneurysm and patency of visceral branches were achieved in around $40 \%$ of aneurysms involving visceral arteries. ${ }^{11,20}$ Although there are reports of reintervention in around $13.7 \%$ of cases, including intestinal resection and thrombosis in $8.3 \%$ of cases, and even rupture of the aneurysm, ${ }^{21,22}$ the technique apparently appears to be promising. ${ }^{20}$ One important limiting factor to use of this material is its cost, which is currently extremely high compared to conventional endoprostheses, particularly by Brazilian standards.

While more significant clinical results are needed to provide better understanding of the possible indications for this technique, some reports and case series that have been published provide guidelines on when the technique should be considered or ruled out, stating that it should not be employed indiscriminately for all patients who do not provide the conditions to be treated using other methods. ${ }^{23-25}$ Successful use of the technique is dependent on respecting strict criteria for indications and conditions, including: previous treatment of stenosis 
of visceral branches; the extremities of the Multilayer stent must lie in normal arteries; where stents overlap, the larger diameter prosthesis must be within the smaller diameter device with oversizing of $15 \%$ to $25 \%$ and at least $60 \mathrm{~mm}$ extension of overlap; mobilization must be minimized, the delivery device must not be rotated inside the artery, extreme angles should be avoided to prevent risk of kinking and the device should not be forced if there is resistance from stenosis or calcifications; the correct size must be chosen according to the manufacturer's recommendations; care must be taken in maneuvering catheters and guide wires inside the aneurysm sac to avoid displacing emboli; care must be taken when withdrawing the delivery device to avoid displacing the Multilayer stent; and double antiplatelet treatment should be maintained for at least 3 months. Multilayer stents are contraindicated for cases of arteriovenous fistulas; vascular outflow insufficiencies; history of coagulation problems; suspected infections; aortic arch aneurysms; pseudoaneurysms and ruptured aneurysms. ${ }^{25}$ In the case described here, indications for treatment with a Multilayer stent were respected and the results exceeded expectations, as was shown by early follow-up imaging exams.

\section{CONCLUSIONS}

Faced with a case involving high operative risk, the option of treating with a Multilayer Flow Modulator appears to be an interesting one because of the ease of execution of this intervention and the promising results described in the international literature. The MFM should not be seen as a miraculous solution for all complex aortic pathologies and criteriabased use is greatly to be encouraged. Although the present case does not offer grounds for any type of recommendation, the results achieved were an important part of accomplishing effective treatment of the patient in question. The technology involved in the MFM is still being studied and we await randomized clinical trials involving several centers and large volumes of cases in order to technically perfect this treatment option and precisely define its indications.

\section{REFERENCES}

1. Bredarioli $M$, Dalio $M B$, Bezerra $C A P$, Piccinato $C E$, Cherri J. Aneurisma de aorta abdominal justa-renal: correção endovascular combinada com derivação ilíaco-renal direita para criar colo proximal adequado. J Vasc Bras. 2007;6(2):182-5. http://dx.doi. org/10.1590/S1677-54492007000200015.

2. Simi A, Ishii R, Ferreira $M$, Santos $A$, Simi AC. Tratamento do aneurisma da aorta toracoabdominal com endoprótese ramificada para as artérias viscerais. J Vasc Bras. 2007;6(1):86-91. http://dx.doi.org/10.1590/S1677-54492007000100013.

3. Kolvenbach RR, Yoshida R, Pinter L, Zhu Y, Lin F. Urgent endovascular treatment of thoraco-abdominal aneurysms using a sandwich technique and chimney grafts-a technical description. Eur J Vasc Endovasc Surg. 2011;41(1):54-60. http:// dx.doi.org/10.1016/j.ejvs.2010.09.013. PMid:20961775

4. Ferrero $E$, Ferri $M$, Viazzo $A$, et al. Visceral artery aneurysms, an experience on 32 cases in a single center: treatment from surgery to multilayer stent. Ann Vasc Surg. 2011;25(7):923-35. http:// dx.doi.org/10.1016/j.avsg.2011.04.006. PMid:21831589

5. Meyer C, Verrel F, Weyer G, Wilhelm K. Endovascular management of complex renal artery aneurysms using the multilayer stent. Cardiovasc Intervent Radiol. 2011;34(3):637-41. http://dx.doi org/10.1007/s00270-010-0047-0. PMid:21107566

6. Benjelloun A, Henry M, Ghannam A, et al. Endovascular treatment of a tuberculous thoracoabdominal aneurysm with the Multilayer stent. J Endovasc Ther. 2012;19(1):115-20. http:// dx.doi.org/10.1583/11-3551.1. PMid:22313211

7. de Vries JP. Treatment of complex thoracoabdominal or juxtarenal aortic aneurysms with a Multilayer stent. J Endovasc Ther. 2012;19(1):125-7. http://dx.doi.org/10.1583/11-3398C.1. PMid:22313213

8. Natrella $M$, Castagnola $M$, Navarretta $F$, et al. Treatment of juxtarenal aortic aneurysm with the Multilayer stent.J Endovasc Ther. 2012;19(1):121-4. http://dx.doi.org/10.1583/11-3398.1 PMid:22313212

9. Balderi A, Antonietti A, Pedrazzini F, Sortino D, Vinay C, Grosso $M$. Treatment of visceral aneurysm using multilayer stent: twoyear follow-up results in five consecutive patients. Cardiovasc Intervent Radiol. 2013;36(5):1256-61. http://dx.doi.org/10.1007/ s00270-013-0705-0. PMid:23934113

10. Flis V, Matela J, Breznik S, Kobilica N. Treatment of primary infected juxtarenal aortic aneurysm with the multilayer stent. Vasc Endovascular Surg. 2013;47(7):561-5. http://dx.doi org/10.1177/1538574413497108. PMid:23922158

11. Henry M, Benjelloun A, Henry I, Wheatley G. The multilayer flow modulator stent for the treatment of arterial aneurysms. J Cardiovasc Surg (Torino). 2013;54(6):763-83. PMid:24126513.

12. Brown B, Ley T. Multi-layer stent. United States patent US 7060089 B2. 2003.

13. Sultan S, Sultan M, Hynes N. Early mid-term results of the first 103 cases of multilayer flow modulator stent done under indication for use in the management of thoracoabdominal aortic pathology from the independent global MFM registry. J Cardiovasc Surg (Torino). 2014;55(1):21-32. PMid:24356043.

14. Pane B, Spinella G, Salcuni M, Palombo D. Stent-graft and multilayer stent for treatment of type II thoracoabdominal aortic aneurysm in a high-risk patient. J Cardiovasc Surg (Torino). 2013;54(4):505-9. PMid:24013540.

15. Knott AW, Kalra M, Duncan AA, et al. Open repair of juxtarenal aortic aneurysms (JAA) remains a safe option in the era of fenestrated endografts. J Vasc Surg. 2008;47(4):695-701. http:// dx.doi.org/10.1016/j.jvs.2007.12.007. PMid:18272317

16. Oderich GS, Mendes BC, Kanamori KS. Technique of implantation and bail-out maneuvers for endovascular fenestrated repair of juxtarenal aortic aneurysms. Perspect Vasc Surg Endovasc Ther. 2013;25(1-2):28-37. http://dx.doi org/10.1177/1531003513512372. PMid:24317632

17. Schneider DB, Curry TK, Reilly LM, Kang JW, Messina LM, Chuter TA. Branched endovascular repair of aortic arch aneurysm with 
a modular stent-graft system. J Vasc Surg. 2003;38(4):855. http:// dx.doi.org/10.1016/S0741-5214(03)01024-3. PMid:14560244

18. Melas N, Perdikides T, Saratzis A, Lazaridis J, Saratzis N. A novel approach to minimize sealing defects: EndoAnchors reduce gutter size in an in vitro chimney graft model. J Endovasc Ther. 2013;20(4):506-13. http://dx.doi.org/10.1583/13-4228C.1. PMid:23914860

19. Niepoth WW, de Bruin JL, Yeung KK, et al. A proof-of-concept in vitro study to determine if EndoAnchors can reduce gutter size in chimney graft configurations.J Endovasc Ther. 2013;20(4):498505. http://dx.doi.org/10.1583/13-4228.1. PMid:23914859

20. Sfyroeras GS, Dalainas I, Giannakopoulos TG, Antonopoulos K, Kakisis JD, Liapis CD. Flow-diverting stents for the treatment of arterial aneurysms. J Vasc Surg. 2012;56(3):839-46. http://dx.doi. org/10.1016/j.jvs.2012.04.020. PMid:22840737

21. Lazaris AM, Maheras AN, Vasdekis SN. A multilayer stent in the aorta may not seal the aneurysm, thereby leading to rupture. J Vasc Surg. 2012;56(3):829-31. http://dx.doi.org/10.1016/j. jvs.2012.03.252. PMid:22819304

22. Ferrero E, Gibello L, Ferri M, Viazzo A, Nessi F. Aortic arch rupture after multiple multilayer stent treatment of a thoracoabdominal aneurysm. J Vasc Surg. 2013. No prelo. http://dx.doi.org/10.1016/j. jvs.2013.08.006. PMid:24199766

23. Sultan $\mathrm{S}$, Hynes $\mathrm{N}$. One-year results of the multilayer flow modulator stent in the management of thoracoabdominal aortic aneurysms and type B dissections. J Endovasc Ther. 2013;20(3):366-77. http://dx.doi.org/10.1583/12-4077MR-R.1. PMid:23731310

24. Vaislic CD, Fabiani JN, Chocron S, et al, and the STRATO Investigators Group. One-year outcomes following repair of thoracoabdominal aneurysms with the multilayer flow modulator: report from the STRATO trial. J Endovasc Ther. 2014;21(1):85-95. http://dx.doi.org/10.1583/13-4553R.1. PMid:24502488

25. Sultan S, Hynes N, Sultan M, and the MFM Collaborators. When not to implant the multilayer flow modulator: lessons learned from application outside the indications for use in patients with thoracoabdominal pathologies. J Endovasc Ther. 2014;21(1):96112. http://dx.doi.org/10.1583/13-4514MR.1. PMid:24502489

\section{Correspondence Rodrigo Gibin Jaldin \\ Departamento de Cirurgia e Ortopedia Faculdade de Medicina de Botucatu Universidade Estadual Paulista - UNESP Av. Prof. Montenegro, s/n - Distrito de Rubião Junior CEP 18618-970 - Botucatu (SP), Brazi E-mail: rgibin@fmb.unesp.br; rgibin@uol.com.br}

Author information

RG) - Vascular and endovascular surgeon, Hospital das Clínicas de Botucatu, Universidade Estadual Paulista (UNESP). Lato sensu degree in Vascular Surgery, Angioradiology, and Endovascular Surgery, and Doppler Vascular Ultrasound. MLS, RM and MB - Assistant professors of Vascular and Endovascular Surgery, Faculdade de Medicina de Botucatu, Universidade Estadual Paulista (UNESP)

JVOM - Vascular surgeon, Hospital das Clínicas de Botucatu, Universidade Estadual Paulista (UNESP).

REFP - Physician, Discipline of Vascular and Endovascular Surgery, Hospital das Clínicas de Botucatu Universidade Estadual Paulista (UNESP).

RAY - Collaborating professor of Vascular and Endovascular Surgery, Faculdade de Medicina de Botucatu, Universidade Estadual Paulista (UNESP)

WBY - Full professor of Vascular and Endovascular Surgery, Faculdade de Medicina de Botucatu, Universidade Estadual Paulista (UNESP).

Author contributions Conception and design: RGJ, MLS, RM, WBY Analysis and interpretation: RGJ, WBY Data collection: RG), REFP, JVOM, MB Writing the article: RGJ, WBY, RAY

Critical revision of the article: RGJ, WBY, RAY, MLS Final approval of the article* RGJ, MLS, RM, MB, REFP, JVOM, RAY,

Statistical analysis: N/A Overall responsibility: RG)

*All authors have read and approved of the final version of the article submitted to I Vasc Bras. 